\title{
4
}

\section{Intentionality and Agency in Values Work Research}

\author{
Thomas Andersson
}

\section{Introduction}

As a professional, I gain autonomy and trust from society because I let certain values guide my actions. And I could of course provide some politically correct description on what these values are. But are these the values that really govern my actions? Well, I guess both yes and no. I mean, I don't think the politically correct values are wrong, but I am certain that I am also governed by values that I am not even aware of. But I guess that is your job as a researcher to help me find out (laughter)? (Transcript from an interview with a physician)

This quotation, I think, presents some of the methodological challenges of trying to understand values and values work in organisations. How can we as researchers or students understand something

\footnotetext{
T. Andersson ( $ه)$

University of Skövde, Skövde, Sweden

VID Specialized University, Oslo, Norway

e-mail: thomas.andersson@his.se 
interviewees cannot fully make sense of themselves, especially if values are implicit, hidden, temporary and conflicting? In this chapter, I will address how we can capture values and values work independently of whether the people in our research can describe them to us or not. As a means to make us more empirically sensitive and capable of capturing values and values work, I will use the concepts of intentionality and agency. Since values work research is a concept within institutional theory (Askeland et al., 2020), the degree of agency is not chosen by the actor. It is the actor's roles and social positions as parts of institutions that influence agency (Abdelnour et al., 2017). Based on the basic definition that actors display agency when they go against the constraints of social structure (Calhoun, 2002), I will avoid a more precise definition and instead portray agency as multi-dimensional (Battilana \& D'Aunno, 2009). If agency is empirically investigated instead of being investigated as a theoretical point of departure (i.e., one-dimensional), we are able to have a much broader view of what intentionality might mean (beyond what the physician in the above quote perceives as intentionality). Intentionality can be seen as salient expressions of values (Aadland, 2010), which means that different dimensions of agency that allow a broader view of intentionality also enable researchers and students to better capture values and values work empirically. I will also elaborate on how these different dimensions of agency have implications for what people's consciousness is directed to, as well as how consciousness is related to personal values and socially imposed values. The aim of this chapter is to elaborate on the meaning of the concepts of agency and intentionality for methodological choices in values work research. The guiding research question of the chapter is as follows: how can researchers and students use the concepts agency and intentionality to enable data collection and interpretation that better captures values work? 


\section{Values and Values Work and Their Relation to Intentionality}

The interest in values work, and not only values, follows Barley and Kunda's (2001) request to 'bring work back in' to research. They argue that work had been marginalised in organisational research. Since their research, work has re-entered organisational research in many new forms, such as emotion work, identity work, institutional work, boundary work and values work (Phillips \& Lawrence, 2012). In common in all these diverse work research streams is that work is directed towards something that is 'worked upon', and this something is socially constructed. As a researcher, this means directing interest towards efforts and actions (work) (Andersson \& Gadolin, 2020) rather than actors/people. Furthermore, it means that concepts such as identity, emotion, institution or value, which previously were more or less taken for granted, now are seen as something that is more actively constructed (and worked upon) (Phillips \& Lawrence, 2012). However, what I find problematic in many work concepts is that they seem to be implicitly grounded in a strong intentionality, which risks being misleading regarding method choices. This is most clearly visible in institutional work, which originally was defined as 'purposive action aimed at creating, maintaining, and disrupting institutions' (Lawrence \& Suddaby, 2006, p. 217; emphasis added). Such strong demands on intentionality, which this definition implies, would leave out much of what could be understood as institutional work just because the people who are performing institutional work did not intend it to be institutional work or were simply not aware of it. In the next section, I will argue for a broader view of intentionality. However, first I would like to emphasise that values work is not so heavily influenced by strong intentionality since Askeland et al. (2020, p. 4) define values work as 'any sets of acts in everyday work [that are] values-driven'. On the contrary, this definition portrays an implicit intentionality in which values are manifested in work and thereby 'worked upon'. However, even if we are under less risk to be misled in terms of method choice by this definition, we still need methods that enable us to capture values and values work that is both explicit and implicit. Then we need to analyse intentionality and its relationship to agency. 


\section{Intentionality and Consequence Versus Appropriateness}

The tendencies to understand 'work' as based on a clear intentionality is based upon a risk that is always present in social sciences: to over-focus on explicit and intended aspects of almost any social concept. Simply because they are easier to capture, people are aware of them and can express them, for example, through interviews. Actors are not always aware of their intentions, and actors' accounts of their intentions are not always reliable (Zilber, 2013). Besides not being aware of intentions, another explanation is that human beings prefer to be able to rationalise. March (1994) argues that this preference for rationality means that we understand organisations and leadership based on a logic of consequence, as we view actions as consequential and preference based. Actions are consequential in the sense that they are the consequences of our anticipations of the future; that is, we have specific intentions that lead our actions. Actions are preference-based in the sense that they are evaluated based on our preferences (what we see as important, unimportant, good, bad, etc.). The logic of consequence describes human actions as based on a very strong and explicit intentionality and values as explicit and articulated (almost outside of us), which makes it possible to objectively evaluate something. Based on this view, values and values work would be perfectly accessible through interviews since people are aware of them and can express them. However, considering the quote at the beginning of the chapter, we should question if we can really capture the whole picture. We would only capture values and values work that are explicit, and values and values work become restricted to rationalised values and values work that may be a foundation to evaluate consequences based on them. There must be something else going on that the logic of consequence cannot describe.

Watson (2006) explains this feeling of something else going on by arguing that rational choice and, thereby, the logic of consequence are poor descriptions of human action. The logic of consequence does not take people's identities into consideration, or interactional relationships between intentions and actions. Actions are not simply an effect of 
intentions, but intentions and actions are matched to each other. Similarly, values do not only inform actions; actions also manifest values (Aadland, 2010). March (1994) presents another view, the logic of appropriateness, that better enables an understanding of people's actions in organisations. It takes into consideration that people want their actions to be aligned with who they are (and/or want to be/become) (Andersson, 2012) and that actions are situational and matched to the situations they appear (in, e.g., organisations) rather than connected to clear expectations of the future (March, 1994). In particular, in complexity and ambiguity, the logic of appropriateness tends to guide human action (Andersson, 2015). When people cannot clearly calculate what to do (as the logic of consequence implies), actions are guided by a reasoning process that establishes identities and matches rules to recognised situations (March, 1994). This reasoning process can be understood as people explicitly or implicitly asking themselves three questions (March, 1994; Andersson, 2015):

1. Recognition: What kind of situation is this?

2. Identity: What kind of person am I?

3. Rules: What does a person such as I do in a situation like this?

This kind of reasoning means that values and values work are not just directly and objectively related to actions and consequences, as in the logic of consequence. They are also more implicitly and subjectively connected to personal values (are these values aligned with whom I want to be?) and situational (and thereby more temporal) values. And even more important, there is the connection between personal and situational values, which opens up for conflicting values. The reasoning process described above is complex and often implicit, which means that values and values work will be much more complex to capture empirically compared to the logic of consequence, which we can quite easily capture through interviews and to which I will return. For now, we can settle with that we will always have more of a challenge in researching values and values work that is more implicit, abstract and indirect.

Intentionality is very clear, explicit and future-oriented (expectations of the future) in the logic of consequence, but does it really mean that 
people do not have intentions based on the logic of appropriateness? Is there no intentionality behind who you want to be and become just as there is in what consequences you want to reach through specific actions? Yes, but the difference is to what extent people can predict and directly influence consequences. We need a broader view of intentionality to capture the intentionality of the logic of appropriateness. The intentionality in the logic of consequence is based on a strong agency, whereas the intentionality in the logic of appropriateness is based on other dimensions of agency, which will be handled next.

\section{Intentionality and Agency}

In institutional work research, the issue of intentionality has been elaborated based on different dimensions of agency (Battilana \& D'Aunno, 2009), which can be seen as a way to deal with more implicit and abstract values and values work in research. Battilana and D'Aunno's (2009) basic argument is that there are different dimensions of agency: projective agency, iterative agency and practical-evaluative agency. Projective agency is the form of agency that is most explicit since it focusses on actors' projections of the future and leads action in that direction. Projective agency is thereby the agency behind the intentionality we can see in the logic of consequence (March, 1994). Iterative agency is related to habits and how previous actions may be reactivated (Battilana \& D’Aunno, 2009). Thereby, this form of agency is more related to the logic of appropriateness (March, 1994) since people's previous experiences influence how they both recognise and interpret different situations, as well as who they are based on a processual view of identity (Andersson, 2015). Practicalevaluative agency is focussed on the present and how actors respond to contingencies they perceive (Battilana \& D'Aunno, 2009). This form of agency is also more related to the logic of appropriateness (March, 1994) since it takes the situational and temporal aspects of everyday work (and life) into consideration. 
Projective agency focusses on purposive actions, which are often represented by managers portraying themselves as leading action in certain directions. Iterative and practical-evaluative agencies are both more implicit and subtle, where intentionality must instead be understood as incorporating a wide range of levels of purposefulness (Battilana \& D'Aunno, 2009). One example may be people's intentions to accomplish their everyday, mundane, practical work. In such intentions, there are most probably no intentions of performing institutional work, but this is not the same as the actions not being intentional; rather, it says something about what the intentions are directed at and what the underlying dimensions of agency are (Andersson \& Gadolin, 2020). In terms of values and values work, most often they are not in the foreground; that is, values and values work are not the main intentions behind certain actions (Aadland, 2010). More often values and values work are implicit and underlying, and they might condition certain actions to different extents. However, values and values work are often important and influence action, especially considering the previous definition of values work as 'any sets of acts in everyday work [that are] values-driven' (Askeland et al., 2020 , p. 4). If values work was in the foreground, it would be more related to projective agency and the logic of consequence, but now we have to deal with it as more related to iterative agency and practicalevaluative agency and the logic of appropriateness, which means that we need methods that enable capturing phenomena that are implicit, hidden and tacit and that people might not be aware of. Furthermore, in terms of importance in influencing action, implicit values may be considered more influential than explicit values. The reason is that people who are aware of certain values are also aware of when these are being challenged and when they have a choice in terms of different values. However, when it comes to more implicit values that may be taken for granted, people may be unaware that there is a choice at all. For this reason, even if capturing hidden and implicit values and values work is much more difficult, it might also be much more important if we want to understand people's actions in organisations. 


\section{Values and Values Work and Social Order}

The challenge related to values often being both hidden and tacit, as Espedal et al. (2021) describe in the introductory chapter of this book and as I have elaborated on in this chapter, is not the only challenge in values work research. Values are also an important part of the social order (Scott, 2013), which means that they are desirable or not desirable in different contexts. The logic of appropriateness brings in the situational aspect (March, 1994), which means that values are not objectively desirable or not, but rather situationally desirable or not. Consequently, differences in what people say and what they do cannot only be explained by to what extent they are aware of different values influencing their actions. It might also depend on to what extent people see certain values as socially desirable or not in their contexts and to what extent they identify with their work roles. Argyris et al. (1985) argue that the difference is not really a difference between theory and action; rather, it is a difference between two different theories of action: espoused theory (the world view and values people believe in and think they base their actions on, which they can and want to espouse) and theory-in-use (the world view and values that actually govern people's actions). If we concentrate on values, there are espoused values (Aadland, 2010) as well as values-in-use that govern people's actions. Argyris et al.'s (1985) two different theories of actions are not mutually exclusive (other than in the extreme situation when what people say and what people do are totally different). Instead, the question is to what extent there are differences in espoused values and values-in-use. These differences can be explained on the one hand by different types of intentionality and on the other hand by to what extent the values represent the social order (i.e., they are socially desirable, and people are willing to openly espouse them). These challenges must be approached when researching values and values work. 


\section{Intentionality, Agency and Their Implications for Qualitative Methods}

This section will elaborate on how the mentioned challenges regarding intentionality and agency condition our choices of methods. In the introductory chapter (Espedal et al., 2021), it is stated that general limitations apply to the use of quantitative methods in researching values, which is why this book has a general focus on qualitative methods in researching values and values work. However, the use of qualitative methods also presents several challenges when considering intentionality and agency. Different qualitative methods have different strengths and weaknesses, but with a combination of different qualitative methods, such weaknesses can be limited. Often, triangulation is used as a metaphor when using mixed methods, but the metaphor indicates that using several methods makes the data 'truer' or 'more correct'. However, when using different qualitative methods, triangulation is a means of leveraging strengths while simultaneously mitigating the weaknesses of several methods (Paul, 1996). I will discuss qualitative interviews, participant observations and shadowing observations as qualitative methods that can be combined to capture values and values work. I begin with describing them individually based on their strengths and weaknesses, as well as how our use of each method can enable us to better capture values and values work empirically and independently of the dimensions of agency and intentionality.

\section{Qualitative Interviews}

Qualitative interviews are preferable when we are interested in how interviewees make sense of the object being studied, in this case values and values work. Furthermore, they are useful when we are not sure what it really is that we are studying, but we need to elaborate on it and increase understanding of the studied case together with the interviewee. We can also use interviews to collect narratives on situations and processes we are interested in. When collecting narratives, it is rather the manifestations of values in actions (or values work) than values per se that we collect. As Alvesson (2011) emphasises, interviews are better suited for capturing 
discursive phenomena (i.e., how people talk) than non-discursive phenomena (e.g., values and values work). Values and values work may be reproduced through the story-telling in an interview, but it is important to be careful when determining how to understand the data material. We will need further analysis to understand what kind of values these stories and actions represent (cf. Watson, 2006), for example, through thematic analysis as described by Wæraas (2021) in this book.

In regard to different dimensions of agency, we tend to receive an overrepresentation of actions based on projective agency in interviews. Consider the following quote from a hospital director in an interview when I asked her to describe her job:

I am in charge of effecting the strategies of the hospital. I work through my management group and in close collaboration with the politicians in the board. Currently, my main attention is directed to the four focus areas to transform our healthcare system in the region.

This statement is based on projective agency; it is about the future and how the director envisions it. However, when I asked her to tell me about her day until the interview, another picture appeared:

Well, I have been running from meeting to meeting, and I have also had problems with my computer. I couldn't access the files on my computer when I came in the morning, but my secretary managed to solve this with our IT support. My secretary can handle them (IT support), which I cannot. Always when I contact them, I wonder if it is me or them who's in charge of the hospital (laughter). The first meeting concerned problems at one of our clinics that we have struggled with for years. We have major problems with recruiting psychiatrists, which influences waiting times for patients, but also quality. The second meeting concerned the collaboration with municipal organisations. We have these meetings every second month to keep the collaboration on track.

When describing her day, she added actions based on iterative and practical-evaluative agencies, which are a major part of her everyday work. My experience is that the higher up in the organisational hierarchy an interviewee is located, the greater the risk of over-representation of 
projective agency in interviews. As interviewers, we need to be attentive to the fact that interviewees act based on habits and perform their work also in an interview (cf. Alvesson, 2011). In this case, the hospital director is used to expressing strong intentionality through talk about strategies and plans, not about her everyday computer problems, and she is likely to do that in the interview as well. To delimit this risk, I usually try to make interviewees talk about specific events and actions rather than abstract plans. Simple questions such as 'Can you give me an example of that?' or 'Can you tell me about when this happened recently?' can take them out of the projective agency mode and encourage them to provide richer descriptions of their everyday work that also involve other dimensions of agency.

Interviews have been heavily criticised since there is a risk they are used in a positivistic sense and in a naïve manner (Alvesson, 2003), as they are seen as producing objective facts. Interviews are seemingly easy to use, and there might be over-use in which interviewers are not really aware of the weaknesses of the method or have naïve assumptions regarding the logic of consequence versus the logic of appropriateness to relate to the previous section. As Czarniawska (2004) makes clear, interviews are not a window to another world. The data that are delivered through an interview are not 'true' or 'facts': they are people's insights about the realities of their practice based on their sense-making and interpretation of situations. In terms of values and values work, what we might capture through interviews may be limited by to what degree interviewees are aware of values and values work, as well as to what extent they are able to express them. Furthermore, as interviewers, we only receive data that the interviewee is willing to share with us, nothing more. Interviews may delimit our empirical material to values and values work that the interviewee perceives as desirable.

What can an interviewer do to delimit the weaknesses of this method, that interviewees only share what they are willing to share (with the risk of espoused values rather than values-in-action) and what they are able to share (to what extent they are aware of certain values)? A qualitative research interview is (or should be) an interaction in which both interviewer and interviewee participate actively. Often, the main focus is on the interviewer, but who is really the expert? Even though the student or 
researcher who performs the interview may be more educated than the interviewee, interviewees know more about their own practices, values and values work. As students or researchers, we should be attentive to what interviewees really say. This may seem self-evident, but many students and researchers fail to pay attention to interviewees' responses because they are too occupied with their interview guides and the questions they should ask next. As Kreiner and Mouritsen (2005, p. 158) claim, 'When interviews fail it is rarely because the interview guide is violated, but because it is not violated!' When interviewing, we must be careful not to disturb the interaction by violating common-sense rules for any interaction. When there is a true interaction between two active and interested actors, trust tends to develop that makes both parties more willing to share. If trust is built, the interviewer might take advantage of the fact that any practitioner, especially those high up in the organisational hierarchy, has few opportunities to think out loud (Czarniawska, 2004) and openly reflect on their practices without the reflection becoming a part of the organisational politics. Without trust, interviewees, and especially managers, may use statements based on projective agency almost as window dressing, to appear to be in control in the interview. With trust, interviews have the potential to become an arena for open reflection, which means that the interviewee might not only be open about their values and values work that are based on other dimensions of agency than projective agency. They might also become conscious about values that govern their actions that they were not previously aware of when reflecting together with the researcher; see the chapter on interviews by Espedal (2021).

\section{Participant Observations and Shadowing Observations}

The previous section describes how interviews can be more effective, but we could also strengthen them or delimit their weaknesses by combining interviews with participant observations and shadowing observations, which will be described in this section. The combination of interviews and observations can delimit the weakness of interviews, namely that interviewees only share what they are willing and able to share. 
Observations entail researchers observing practices as they unfold, which means observing practices that the practitioner in an interview maybe did not want to share, was not aware of or did not see as important. However, concerning researching values and values work, we can observe actions and practices, but not values, directly. To access values, we have to analyse what the practice might represent (in terms of values), which can be done through, for example, thematic analysis if the observations are transferred to observation protocols (and thereby texts). As students or researchers, we can perform this analysis by ourselves, but we can do it even better together with practitioners. Ethnographers (e.g., Hammersley \& Atkinson, 1995) often argue that interviews should accompany observations. The interview can then become a joint elaboration of a shared experience, where the interviewer and interviewees together reflect upon values that are manifested by certain actions. The challenge with all observations is that they produce a lot of data, much of which is of less use compared to interviews, which tends to be more time efficient. This is another reason why these methods should be combined.

Choosing the arena for participant observation is maybe the most important preparation before an observation. If the aim is to research values and values work, the observation site should be likely to produce manifestations of values and values work. Furthermore, values are often most easily accessible when they are challenged (Seo \& Creed, 2002) since they otherwise tend to be less salient. In what arenas are values most likely to become manifested and/or challenged? In what arenas may values work be the most explicit? Such questions should guide the choice of observation site. On the other hand, a weakness with such observations is that the researcher chooses a particular site, which displays only a part of what is going on in the organisation. One way to limit that weakness is to combine it with shadowing observations (Czarniawska, 2007). Shadowing means following a practitioner in his/her daily work, which means attending many different potential sites of observation. Shadowing also often means opportunities to interact with the shadowed practitioner, similar to several ad hoc interviews, with the opportunity to leverage the two methods. Similar to the combination of observations in meetings with interviews, ad hoc interviews during shadowing observation might become shared reflections on values-in-use in the observed practice (Sirris et al., 2021). 


\section{Combining Methods to Capture Different Forms of Agency}

Different dimensions of agency related to values work require different data collection methods. Interviews are feasible to capture values work based on projective agency since people tend to be aware of and able to express such actions. However, considering people's tendencies to rationalise (March, 1994), we might still risk receiving people's retrospective rationalisations. The most difficult task is to capture values work based on iterative or practical-evaluative agency via interviews. Such values work can better be captured by observations, such as participant observations or shadowing. In particular, practical-evaluative agency almost always requires observation, with actors responding to contingencies they perceive here and now. Iterative agency may require a combination of interviews and observations since it may be possible to capture a response by observation but not the habit it is reactivating. In general, since dimensions of agency present rather an empirical question than something we should view as a point of departure, research on values work always gains from combining interviews and observations. If we could easily determine agency in advance, we could say which data collection method is more appropriate in certain situations, but in reality, it is difficult. An approximation is that the stronger the social position, the more projective agency is demonstrated. However, better safe than sorry: using a combination of methods enables us to capture values work independent of which dimension of agency it is based upon. If interviews are made after observations, the observations provide actions and situations to discuss in the interviews, but on the other hand, interviews before observations might make it easier to understand what we are observing. Consequently, if the research design allows it, there are advantages to moving back and forth between interviews and observations throughout the period of data collection. 


\section{Conclusion}

There are many advantages to using qualitative methods in research on values and values work, but that does not mean that it is easy. Values and values work are not easily captured since they might be implicit, abstract, hidden, temporal or situational. In this chapter, I have elaborated on some challenges based on intentionality and agency and how researchers and students can combine different qualitative methods to make use of each method's strengths while mitigating each method's weaknesses. If researchers and students understand intentionality and agency better, they will be better prepared to avoid the risk of over-representation of intentions based on strong projective agency during data collection. There is a need to be attentive to subtler dimensions of agency, namely iterative agency and practical-evaluative agency, for which intentions are not explicitly related to certain values or values work but for which values work may be an unintended effect of trying to do one's work as best as one can. People are to different extents aware of their personal values and the values work that they perform.

Combining interviews and observations means that researchers and students are better prepared to capture values and values work independently of which intentionality and agency they are based upon. Interviews are effective at capturing values and values work based on strong, projective agency, but they risk over-representing them in the data material; meanwhile, observations enable us to capture values and values work based on subtler iterative agency, as well as unconscious and undesirable values. Practical-evaluative agency requires both interviews and observations, which in general strengthens our understanding of intentionality based on any of the other dimensions of agency.

\section{References}

Aadland, E. (2010). Values in professional practice: Towards a critical reflective methodology. Journal of Business Ethics, 97(3), 461-472.

Abdelnour, S., Hasselbladh, H., \& Kallinikos, J. (2017). Agency and institutions in organization studies. Organization Studies, 38(12), 1775-1792. 
Alvesson, M. (2003). Beyond neopositivists, romantics, and localists: A reflexive approach to interviews in organizational research. Academy of Management Review, 28(1), 13-33.

Alvesson, M. (2011). Interpreting interviews. Sage.

Andersson, T. (2012). Normative identity processes in managers' personal development training. Personnel Review, 41(5), 572-589.

Andersson, T. (2015). The medical leadership challenge in healthcare is an identity challenge. Leadership in Health Services, 28(2), 83-99.

Andersson, T., \& Gadolin, C. (2020). Understanding institutional work through social interaction in highly institutionalized settings: Lessons from public healthcare organizations. Scandinavian Journal of Management, 36(2), 101107.

Argyris, C., Putnam, R., \& McLain Smith, D. (1985). Action science: Concepts, methods, and skills for research and intervention. Jossey-Bass.

Askeland, H., Espedal, G., Løvaas, B. J., \& Sirris, S. (2020). Understanding values work. Springer.

Barley, S. R., \& Kunda, G. (2001). Bringing work back in Organization. Science, 12(1), 76-95.

Battilana, J., \& D'Aunno, T. (2009). Institutional work and the paradox of embedded agency. In T. Lawrence, R. Suddaby, \& B. Leca (Eds.), Institutional work: Actors and agency in institutional studies of organizations (pp. 31-58). Cambridge University Press.

Calhoun, C. (Ed.). (2002). Dictionary of social sciences. Oxford University Press.

Czarniawska, B. (2004). Narratives in an interview situation. In B. Czarniawska (Ed.), Narratives in social science research (pp. 47-59). Sage Publications.

Czarniawska, B. (2007). Shadowing: And other techniques for doing fieldwork in modern societies. Copenhagen Business School Press DK.

Espedal, G. (2021). Research interviews to investigate and co-create value. In G. Espedal, B. Jelstad Lövaas, S. Sirris, \& A. Wæraas (Eds.), Researching values. Methodological approaches in understanding values work in leadership and organizations. Palgrave Macmillan.

Espedal, G., Jelstad Løvaas, B., Sirris, S., \& Wæraas, A. (2021). Introduction. In G. Espedal, B. Jelstad Lövaas, S. Sirris, \& A. Wæraas (Eds.), Researching values. Methodological approaches in understanding values work in leadership and organizations. Palgrave Macmillan.

Hammersley, M., \& Atkinson, P. (1995). Ethnography. Principles in practice (2nd ed.). Routledge. 
Kreiner, K., \& Mouritsen, J. (2005). The analytical interview. In S. Tengblad, R. Solli, \& B. Czarniawska (Eds.), The art of science (pp. 153-176). Liber \& Copenhagen Business School Press.

Lawrence, T., \& Suddaby, R. (2006). Institutions and institutional work. In S. Clegg, C. Hardy, T. Lawrence, \& W. R. Nord (Eds.), Handbook of organization studies (2nd ed., pp. 215-254). Sage.

March, J. G. (1994). A primer on decision making: How decisions happen. Simon and Schuster.

Paul, J. (1996). Between-method triangulation in organizational diagnosis. International Journal of Organizational Analysis, 4, 135-153.

Phillips, N., \& Lawrence, T. B. (2012). The turn to work in organization and management theory: Some implications for strategic organization. Strategic Organization, 10(3), 223-230.

Scott, W. R. (2013). Institutions and organizations: Ideas, interests, and identities. Sage Publications.

Seo, M. G., \& Creed, D. (2002). Institutional contradictions, praxis, and institutional change: A dialectical perspective. Academy of Management Review, 27(2), 222-247.

Sirris, S., Lindheim, T., \& Askeland, H. (2021). Observation and shadowing: Two methods to research values in organisations and leadership. In G. Espedal, B. Jelstad Løvaas, S. Sirris, \& A. Wæraas (Eds.), Researching values. Methodological approaches in understanding values work in leadership and organizations. Palgrave Macmillan.

Wæraas, A. (2021). Thematic analysis: Making values emerge from texts. In G. Espedal, B. Jelstad Løvaas, S. Sirris, \& A. Wæraas (Eds.), Researching values. Methodological approaches in understanding values work in leadership and organizations. Palgrave Macmillan.

Watson, T. (2006). Organising and managing work: Organisational, managerial and strategic behaviour in theory and practice (2nd ed.). Pearson Education.

Zilber, T. (2013). Institutional logics and institutional work: Should they be agreed? In M. Lounsbury \& E. Boxenbaum (Eds.), Institutional logics in action (39A ed., pp. 77-96). Emerald. 
Open Access This chapter is licensed under the terms of the Creative Commons Attribution 4.0 International License (http://creativecommons.org/licenses/ by/4.0/), which permits use, sharing, adaptation, distribution and reproduction in any medium or format, as long as you give appropriate credit to the original author(s) and the source, provide a link to the Creative Commons licence and indicate if changes were made.

The images or other third party material in this chapter are included in the chapter's Creative Commons licence, unless indicated otherwise in a credit line to the material. If material is not included in the chapter's Creative Commons licence and your intended use is not permitted by statutory regulation or exceeds the permitted use, you will need to obtain permission directly from the copyright holder.

(c) (i) 